\title{
Running Stability Test and Impact Analysis of Noise Automatic Monitoring System
}

\author{
Tang Xiao, Li Danian, Yu Jiayan \\ ( Chongqing Envionmental Center, Chongqing 401147, China)
}

Key words: environmental noise; automatic monitoring instrument; calibration cycle

\begin{abstract}
With the wide application of environmental noise automatic monitoring technology in our country cities have established environmental noise automatic monitoring system. But due to the country is not about the technical specification of automatic monitoring, calibration of the system and a series of quality control and quality assurance, cities are at their respective groping stage. Eliminate the effect of temperature on the current our country several mainstream environmental noise automatic monitoring instrument to carry on the calibration cycle test, end up with a reasonable calibration cycle, for your reference.
\end{abstract}

\section{Introduction}

With the development of electronic science and technology and the rising power of national economy, in order to meet the needs of environmental management and public information, China's major cities have established environmental noise automatic monitoring system one after another. Noise automatic monitoring instrument is the basis of implementing noise automatic monitoring, the quality control and quality assurance work of its system directly determine the precision of noise automatic monitoring data. Because at present there isn't a technical specification related with noise automatic monitoring in our country yet, the environmental monitoring departments at all levels are still in the stage of respective grope, induction and summary about the operating maintenance of noise automatic monitoring system. According to Notice of the Implementation Work of 2013 National Environmental Protection Standards Project ( Letter of environmental office [ 2013 ] no . 154), China National Environmental Monitoring Center has carried out the formulation work of the standard project the Technical Specification for the Function Region Environmental Quality Automatic Monitoring, and Chongqing Station has participated in the test research on the rationality of calibration cycle for the environmental noise automatic monitoring instrument in the quality control and quality assurance of the technical specification so as to make the relevant technical personnel carry out the quality control and quality assurance of noise automatic monitoring and provide the reference for the country to formulate the relevant technical specifications.

\section{Development of the Environmental Noise Monitoring Technology}

Domestic sound environment automatic monitoring work started in the 1980s. Some of the earliest cities set up the noise screen with the display function mostly on the traffic trunk roads, so the prototype of the noise automatic monitoring has formed. State Environmental Protection Administration has put forward the following words in Environmental Monitoring Technical Route( Environmental Office [2003]no. 49), "Use the environmental noise automatic monitoring instrument and other equipment with the automatic sampling function to carry out the noise monitoring of functional regions according to continuous monitoring method at the stages and fixed points. Urban environmental noise monitoring network with perfect functions and automatic monitoring network system with the key traffic source should be built around our country." GB 3096-3096 "Standards for Sound Environmental Quality" had been issued and implemented in October 2008. It clearly put forward in the standard that national key environmental protection cities and other cities and regions with the proper conditions are suitable to set up the environment 
noise automatic monitoring system for the continuous automatic monitoring of different monitoring points of sound environment in functional regions. With the application and improvement of noise automatic monitoring technology, the environmental noise automatic monitoring will be placed on the agenda faster. In September, 2011 Technical Requirements for Environmental Noise Automatic Monitoring System ( tentative regulation) and Technological Regulations of Automatic Monitoring for Sound Environment in Function Regions (tentative regulation), the two tentative technical regulations had been issued so as to promote the process of noise automatic monitoring, and dozens of cities across the country began to carry out the noise automatic monitoring work one after another. For example, in 2006 Shanghai built the noise automatic monitoring system with the points of 16 stations. In 2007, in order to welcome the Olympic Games in Beijing and ensure the quality of sound environment, the capital built 108 sets of noise automatic monitoring system which can cover each functional region in Beijing city. In 2008 , Chongqing built the noise automatic monitoring system with the points of 21 stations in the functional region. What's more, the cities which have built the automatic monitoring systems and made them run are the following cities, such as Nanjing, Guangzhou, Shenzhen, Zhuhai, wuhan, Hohhot, Nanchang, Suzhou, and other most capital cities. These things above can be found in literature about the numbers and purposes of building the noise automatic stations for each region. In recent years, the building of noise automatic stations has gotten some achievements. The building and running of noise automatic monitoring system reflect the dynamic change of sound environmental quality in cities comprehensively and objectively so as to provide more accurate information of sound environmental quality and the results of evaluation and analysis for the administrative department in charge of sound environmental quality and offer the powerful technical support for establishing the related policies of regional assessment and noise pollution control. Thus, it can promote the improvement of sound environment quality truly. In recent years, many domestic scholars have done a lot of researches in the field of noise automatic monitoring. For example, in the aspect of city sound environment prediction they have done a lot of researches so as to establish the corresponding noise prediction models and the urban noise maps and do the researches on the physical constitution of noise automatic monitoring system, the layout optimization of monitoring points, the valid time of monitoring and the monitoring evaluation method, the environmental impact in the actual building of noise automatic monitoring points, etc.

Table 1-1 Domestic Application of Noise Automatic Monitoring System

\begin{tabular}{|c|c|}
\hline Cities & $\begin{array}{c}\text { Number of Automatic Stations } \\
\text { (set) }\end{array}$ \\
\hline Beijing & 108 \\
\hline Shanghai & 16 \\
\hline Chongqing & 21 \\
\hline Guangdong Province & 71 \\
\hline Jiangsu Province & 86 \\
\hline Hubei Province & 20 \\
\hline Yunnan Province & 32 \\
\hline Liaoning Province & 38 \\
\hline Inner Mongolia & 27 \\
\hline
\end{tabular}

Noise automatic monitoring is the development direction of environmental protection. Seen from the requirements of noise related standards and policies and regulations we know that China is moving toward the development of environmental noise automatic monitoring in key environmental protection cities.

In 2003 State Environmental Protection Administration put forward the following words in Environmental Monitoring Technical Route, "With the continuous monitoring method according to different stages and fixed points, use the environmental noise automatic monitoring instrument and other equipment with functions of automatic acquisition to do the noise monitoring in the functional regions, and build the urban environmental noise monitoring network with the 
perfect function and the automatic monitoring network system with the key traffic source around the country.

The Sound Environmental Quality Standard (GB3096-2008) have stipulated the building of noise automatic monitoring system with the following words, "National key environmental protection places and other cities and regions with proper conditions is suitable to set up the environment noise automatic monitoring system so as to do the continuous automatic monitoring of different monitoring points in the function regions of sound environments".

Environmental Noise Monitoring Technology Route issued by China National Environmental Monitoring Center in 2010 clearly put forward in the overall objectives, "By the end of 'twelfth five-year' the various functional regions and road traffics of key environmental protection cities implement the noise automatic monitoring”.

Environment and Development [2010] no. 144 Guidance of Improving Sound Environmental Quality of Urban and Rural Areas about Strengthening Environmental Noise Pollution Prevention and Control Work issued by Ministry of Environmental Protection jointed with 11 Chinese ministries in 2010 clearly put forward in the Chapter of Strengthening the Supervision and Support Capacity Building, " Cities shall establish and perfect the sound environmental quality monitoring network, and consider the noise monitoring as one of the important content of environmental monitoring standardized building. Key noise pollution sources shall install noise automatic monitoring instrument to make the monitoring data be taken as the basis of law-enforcing supervision. By the end of 2011 the cities should set up at least one noise display screen."

Facing the national requirement for environmental noise automatic monitoring, we badly need to the relevant standards and norms of noise automatic monitoring so as to specify the noise automatic monitoring in our country from the monitoring method to the monitoring hardware and software system technology.

We introduce the reason of research project. This research is that part of this project and I will tell you what the purpose is. Then we will describe the main process and the final purpose.

\section{Environmental Noise Automatic Monitoring System}

Environmental noise automatic monitoring system mainly includes three parts, namely automatic monitoring substation, data transmission system and the monitoring center. Automatic monitoring substation is composed of noise monitoring terminal, all-weather outdoor microphone unit, data transmission equipment, meteorological monitoring auxiliary units, fixed station infrastructure, etc. Monitoring center is mainly composed of data communication server, data storage server, management system, information publishing system, etc.

Environmental noise automatic monitoring system generally has the sound measurement precision of Level One. Thus, it can do noise measurement of A, C various frequencies weighting and F, S, I various time weighting, and it can measure Leq and other broadband noise data and 1/1, 1/3 octave band sound pressure level, and it can detect and use MP3 to record the noise events, and it also can so the remote settings and calibration. At the same time, diversified management software can perform the analysis, statistics, fault alarm and GIS display on the automatically uploaded monitoring data from many angles. In recent years the development of Noise automatic monitoring system trends to miniaturization, network and intelligence. Currently the manufacturers of the world's major environmental noise automatic monitoring instruments are listed as follows, Denmark B\&K, France $01 \mathrm{db}$, Norway Norsonic, Japan rion, China Hangzhou Aihua, China's zhuhai Gaoling, etc.

Main products are widely used two kinds of single frequency sound level calibrator to calibrate the microphone. One is $94 \mathrm{~dB}-1000 \mathrm{~Hz}$, and the other is $114 \mathrm{~dB}-1000 \mathrm{~Hz}$. 


\section{Experimental Instruments and Method}

\section{Experimental Instruments}

In order to feel out the performance of various noise automatic monitoring instruments on the market currently, after the inspection, we choose each of imported and domestic instruments with the domestic mainstream application as the representative instruments to do the testing research.

Table 2-1 Type and Quantity of Experimental Instruments

\begin{tabular}{|c|c|}
\hline Instrument Type & Quantity \\
\hline Instrument A (Imported ) & 2 sets \\
\hline Instrument B (Domestic) & 2 sets \\
\hline
\end{tabular}

\section{Experimental Sites}

Considering the safety of instruments and equipment, we select the station 1 and station 2 in the noise monitoring network of Chongqing main city function region as the test sites. And the two test sites both belong to the Type II area of sound environmental quality in function region.

\section{Experimental Time}

The test time is from August 1, 2013 to November 31, 2013.

\section{Experimental Methods}

Before the experiment of instrument calibration cycle test, we should calibrate the standard sound source $94 \mathrm{~dB}$ sound about the four noise monitoring instruments of the two stations on July 24, 2013 and on July 31, 2013 respectively to make sure that the four monitoring instruments perform the test experiment under the same benchmark conditions. Sound calibration results are as follows.

Table 2-2 Instruments Calibration Results

\begin{tabular}{|c|c|c|c|c|c|c|}
\hline $\begin{array}{l}\text { Station } \\
\text { Name }\end{array}$ & $\begin{array}{l}\text { Instrume } \\
\text { nt Name }\end{array}$ & $\begin{array}{c}\text { Calibratio } \\
\text { n Date }\end{array}$ & $\begin{array}{l}\text { Calibratio } \\
\text { n Value } 1\end{array}$ & $\begin{array}{l}\text { Calibratio } \\
\text { n Value } 2\end{array}$ & $\begin{array}{l}\text { Calibratio } \\
\text { n Value } 3\end{array}$ & Note \\
\hline \multirow{2}{*}{$\begin{array}{c}\text { Station } \\
1\end{array}$} & $\begin{array}{c}\text { Instrume } \\
\text { nt A }\end{array}$ & 7.24 & 93.9 & 93.8 & 94.0 & \multirow{4}{*}{$\begin{array}{c}\text { Standard } \\
\text { Sound Source } \\
\text { 94dB (Japan } \\
\text { CAL21) }\end{array}$} \\
\hline & $\begin{array}{c}\text { Instrume } \\
\text { nt B }\end{array}$ & 7.24 & 93.7 & 93.9 & 94.0 & \\
\hline \multirow{2}{*}{$\begin{array}{c}\text { Station } \\
1\end{array}$} & $\begin{array}{c}\text { Instrume } \\
\text { nt A }\end{array}$ & 7.31 & 93.9 & 94.0 & 94.0 & \\
\hline & $\begin{array}{c}\text { Instrume } \\
\text { nt B }\end{array}$ & 7.31 & 94.2 & 94.1 & 94.0 & \\
\hline
\end{tabular}

After the calibration, we should begin to do the stability testing experiment on the four sets of noise monitoring instruments. We should hood Japan CAL21 Type 94dB standard sound source on the microphones of Instrument A and Instrument B of the two stations respectively every day to record the test values and the weather situation at that time. According to the test values of four months, we can analyze the monitoring data of each instrument every day. With the reference to the stipulation of Sound Environmental Quality Standard( GB 3096-2008)and Routine Monitoring of Urban Sound Environment with Environmental Noise Monitoring Technology Specification

(HJ 640-2012) we can use the standard, "Before and after the test deviation of the test value is not more than $0.5 \mathrm{~dB}$ ( A )", to assess whether the instrument needs to do the artificial sound calibration. Does 0.5dB have the source or not? We need to introduce it. 


\section{Analysis of Experimental Results}

With the testing comparison of four months during the four months the running of 4 instruments are all relatively stable. We choose five days to do the test experiment for every week. Eliminating the influence of adverse weather factors, such as rainy days, nearly 250 valid test data are obtained in the experiment. The statistics for experiment results can be seen in Table 2 and Table 3. The test values of two kinds of instrument are shown in Figure 1.

Table 4-1 The Largest Deviation Statistics of Noise Monitoring Instruments

\begin{tabular}{|c|c|c|c|c|}
\hline & \multicolumn{3}{|c|}{ The Largest Deviation (dB) } \\
\hline \multirow{3}{*}{ Months } & \multicolumn{2}{|c|}{ Station 1 } & \multicolumn{2}{c|}{ Station 2 } \\
\cline { 2 - 5 } & $\begin{array}{c}\text { Instrument } \\
\text { A }\end{array}$ & $\begin{array}{c}\text { Instrumen } \\
\text { t B }\end{array}$ & $\begin{array}{c}\text { Instrument } \\
\text { A }\end{array}$ & $\begin{array}{c}\text { Instrument } \\
\text { B }\end{array}$ \\
\hline 8 & 0.3 & 0.2 & $-0.1 / 0.1$ & -0.3 \\
\hline 9 & $-0.3 / 0.3$ & -0.3 & -0.3 & 0.3 \\
\hline 10 & 0.1 & -0.6 & -0.1 & -0.3 \\
\hline 11 & -0.2 & -1.4 & -0.1 & -0.5 \\
\hline
\end{tabular}

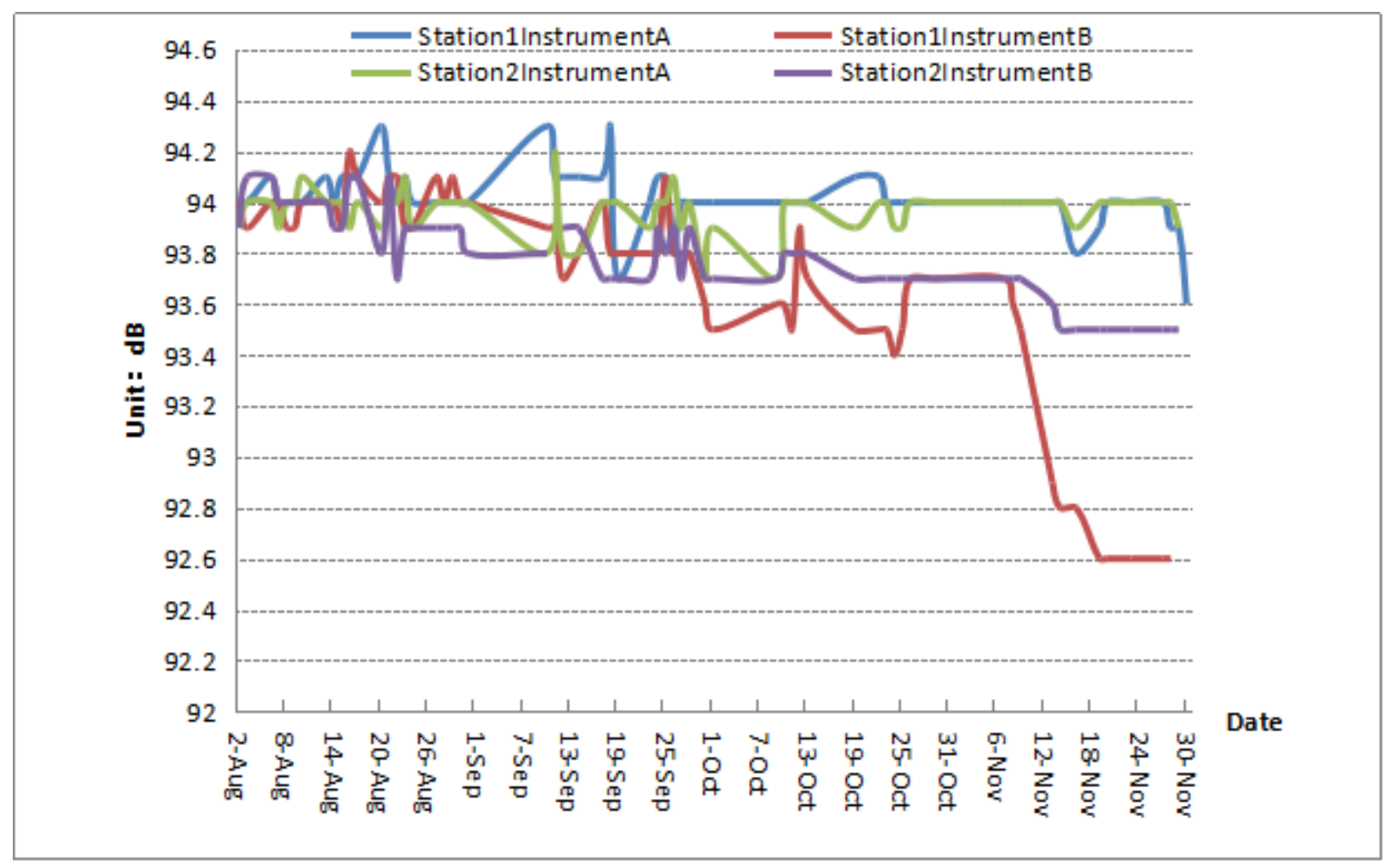

Figure 1 Test Value Trend of Instruments in the Two Stations

From the Table 3-1 and Figure 1, we can see that the fluctuation for the test value of Instrument B with two stations is not big, and during the period the largest deviation range is $-0.3 \sim 0.3 \mathrm{~dB}$ (A) . So the test values are all not over the required value $0.5 \mathrm{~dB}$ (A) stipulated in the Routine Monitoring of Urban Sound Environment with Environmental Noise Monitoring Technology Specification (HJ 640-2012). However, since the third months, the largest deviation value of Instrument B in station 1 is $-0.6 \mathrm{~dB}$ ( A) which is over $0.5 \mathrm{~dB}$ (A) stipulated in the standard. It shows that the stability of Instrument $\mathrm{B}$ begins to decline. In the fourth month, the test values of Instrument $\mathrm{B}$ in the two stations are all over $0.5 \mathrm{~dB}$ (A) stipulated in the standard. It shows that the data reliability of Instrument B is not good. By the end of the third months we need to do the artificial sound 
calibration on the instruments.

During the four months the test value of Instrument A with two stations is relatively stable and the fluctuation range is not big, and during the period the largest deviation range is $-0.3 \sim 0.3 \mathrm{~dB}(\mathrm{~A})$. So the test values are all not over the required value $0.5 \mathrm{~dB}$ (A) stipulated in the Routine Monitoring of Urban Sound Environment with Environmental Noise Monitoring Technology Specification (HJ 640-2012).

Table 4-2 The Standard Deviation Statistics of Noise Monitoring Instruments

\begin{tabular}{|c|c|c|c|c|c|c|c|c|}
\hline \multirow[b]{3}{*}{$\begin{array}{l}\text { M } \\
\text { ont } \\
\text { hs }\end{array}$} & \multicolumn{8}{|c|}{ SD(\%) } \\
\hline & \multicolumn{4}{|c|}{ Station 1} & \multicolumn{4}{|c|}{ Station 2} \\
\hline & $\begin{array}{c}\text { Instrumen } \\
\text { t A }\end{array}$ & $\begin{array}{c}\mathrm{Sa} \\
\mathrm{mpl} \\
\mathrm{e} \\
\mathrm{Nu} \\
\mathrm{mb} \\
\mathrm{er}\end{array}$ & $\begin{array}{c}\text { Instrume } \\
\text { nt B }\end{array}$ & $\begin{array}{c}\mathrm{Sa} \\
\mathrm{mpl} \\
\mathrm{e} \\
\mathrm{Nu} \\
\mathrm{mb} \\
\mathrm{er}\end{array}$ & $\begin{array}{c}\text { Instrument } \\
\text { A }\end{array}$ & $\begin{array}{c}\mathrm{Sa} \\
\mathrm{mpl} \\
\mathrm{e} \\
\mathrm{Nu} \\
\mathrm{mb} \\
\mathrm{er}\end{array}$ & $\begin{array}{c}\text { Instrume } \\
\text { nt B }\end{array}$ & $\begin{array}{c}\mathrm{Sa} \\
\mathrm{mp} \\
\mathrm{le} \\
\mathrm{Nu} \\
\mathrm{mb} \\
\mathrm{er}\end{array}$ \\
\hline 8 & 0.07 & 22 & 0.08 & 22 & 0.06 & 22 & 0.11 & 22 \\
\hline 9 & 0.16 & 15 & 0.11 & 13 & 0.14 & 16 & 0.09 & 16 \\
\hline 10 & 0.04 & 12 & 0.13 & 12 & 0.05 & 11 & 0.05 & 11 \\
\hline 11 & 0.12 & 13 & 0.49 & 13 & 0.04 & 12 & 0.09 & 12 \\
\hline
\end{tabular}

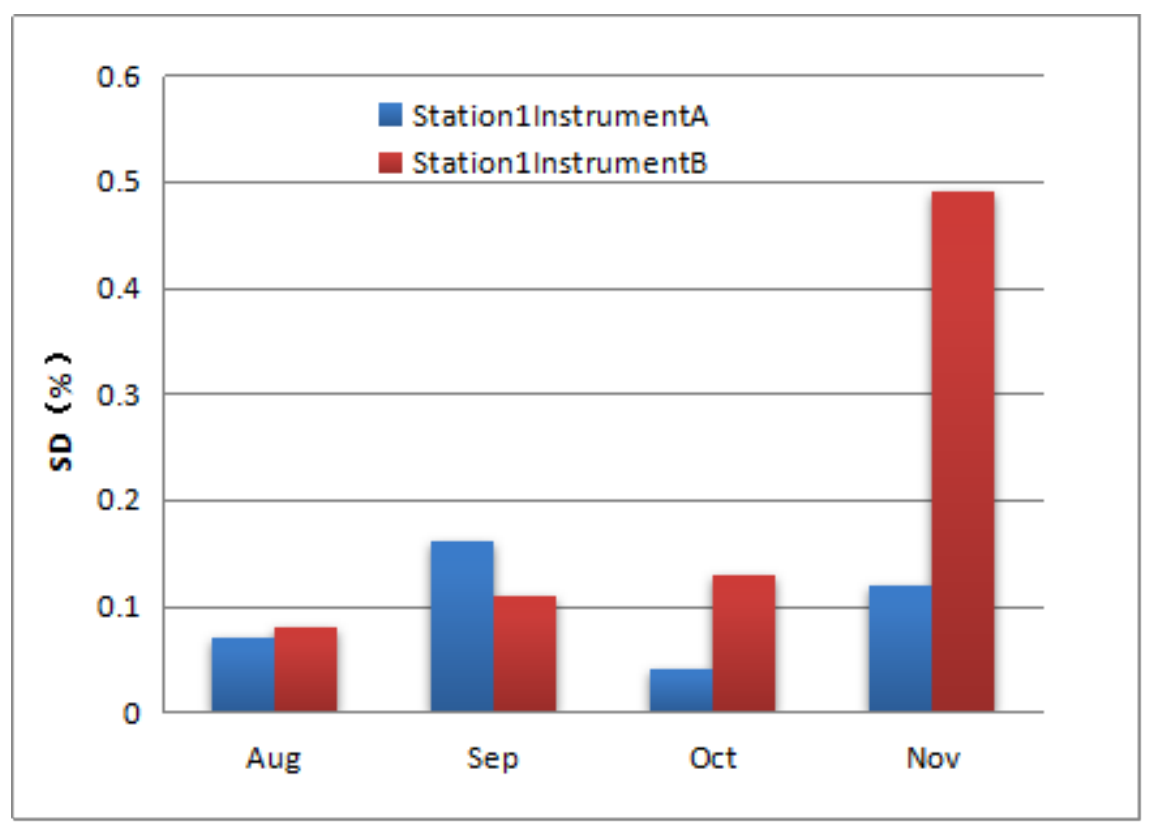

Figure 2 The Comparison of Standard Deviation for the Two Instruments in Station 1 


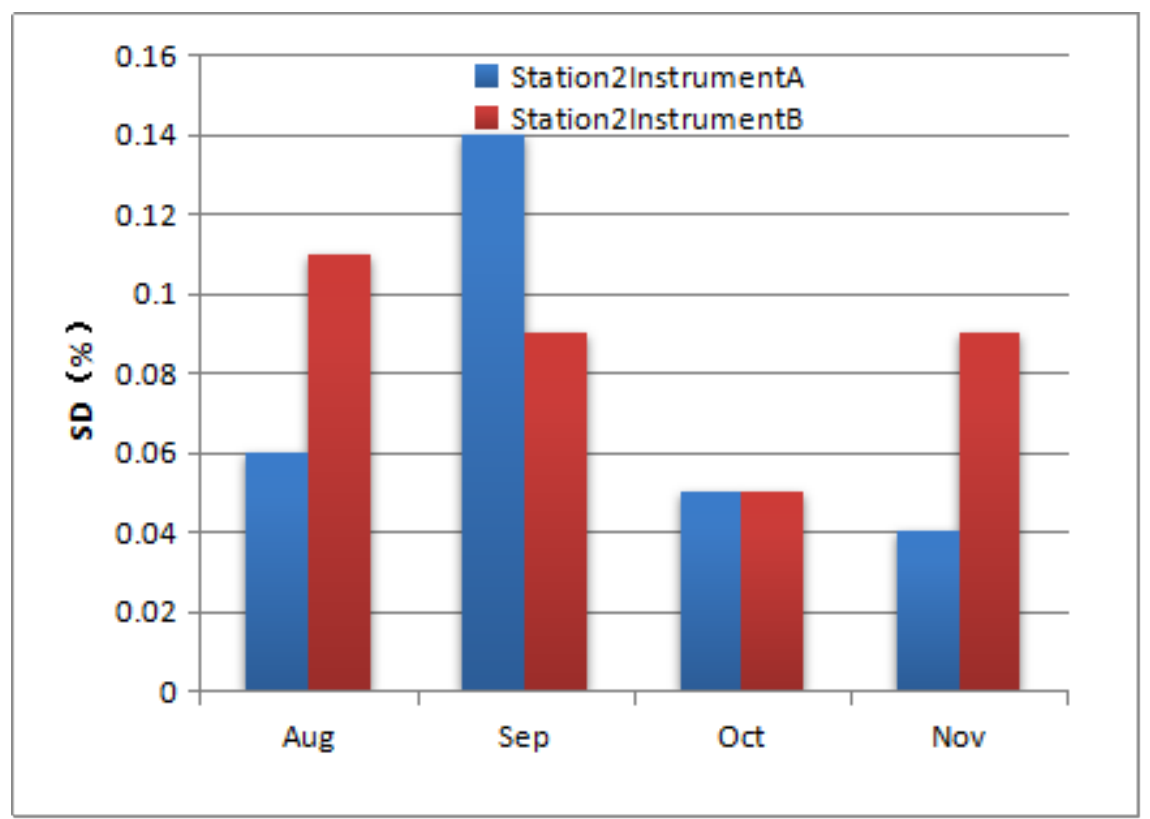

Figure 3 The Comparison of Standard Deviation for the Two Instruments in Station 2

Seen from the standard deviation statistical results of test values for the two instruments during the test period shown in Table 3 we know that under the condition of almost the same sample number the relative standard deviation range of the data from Instrument $A$ is $0.04 \sim 0.16$. However, the relative standard deviation range of the data from Instrument $B$ is $0.05 \sim 0.49$. It is significantly greater than the data statistics result of Instrument $A$. It shows that the running stability of Instrument B is worse than Instrument A.

\section{Conclusion}

The research of noise automatic monitoring instrument calibration cycle test in this paper belongs to a part of the research content in national standards project for environmental protection Function Region Sound Environment Automatic Monitoring Technology Specification.

With the automatic monitoring instrument calibration cycle test for the two kinds of noises this time it shows that during the test time of four months the test values of Instrument $A$ and Instrument B both have obvious change. By the end of the third month the test value of Instrument $\mathrm{B}$ is over the required value $0.5 \mathrm{~dB}$ (A) stipulated in the Routine Monitoring of Urban Sound Environment with Environmental Noise Monitoring Technology Specification (HJ 640-2012). During the test period the fluctuation range for the test values of Instrument A is not big, they are all not over the required value $0.5 \mathrm{~dB}$ (A) stipulated in the Routine Monitoring of Urban Sound Environment with Environmental Noise Monitoring Technology Specification (HJ 640-2012). The stability of Instrument A in the two stations is better than the instrument B.

In addition, according to the experiment results this time we suggest that the environmental noise automatic monitoring instruments should be manually calibrated for at least once per quarter. Of course, the calibration cycle of environmental noise automatic monitoring instruments can also be adjusted flexibly according to specific circumstances. In this way it can ensure that the noise automatic monitoring data are accurate and reliable.

\section{Acknowledgements}

Fund Program: Funded by National standards for environmental protection project "Function Region Sound Environment Automatic Monitoring Technology Standard" 


\section{References}

[1] Devies Jw, Prosky L, Li B. A historical perspective on defining dietary fiber[J]. Cereal Food World, 1999, 44 (5): 367-369.

[2] Anderson J W, Baird P. Health benefits of dietary fiber [J]. Nutrition Reviews, 2009, 67 (4): 188-205.

[3] Wang Siyuan, Qi Junru, Yang Xiaoquan. Effect of soybean polysaccharide on rice starch gelatinization and gel properties[J]. 2011, 30(7): 155-158.

[4] Luo Xuegang. Preliminary study on the application of high-strength edible konjac glucomannan film[J]. Natural Product Research and Development, 2000, 12 (4): 12-16.

[5] Guo Qiaoling, Xie Jianhua, Pang Jie. Study on the Effect of coating and cold shock treatment on the quality of Guanxi pomelo [J]. Preservation and Processing Technology, 2007, 7 (2): 17-19. 